Article

\title{
From Mice to Men: An Evolutionary Conserved Breakdown of the Epidermal Calcium Gradient and Its Impact on the Cornified Envelope
}

\author{
Maria Karolin Streubel ${ }^{1}$, Claudia Neuhofer ${ }^{1}$, Johannes Bischof ${ }^{1}$, Peter Steinbacher ${ }^{1}$, \\ Elisabeth Russe ${ }^{2}$, Gottfried Wechselberger ${ }^{2}$, Klaus Richter ${ }^{1, *}$ and Mark Rinnerthaler ${ }^{1, *}$ (i) \\ 1 Department of Bioscienses, University of Salzburg, 5020 Salzburg, Austria; \\ karolinstreubel@googlemail.com (M.K.S.); Claudia.neuhofer@stud.sbg.ac.at (C.N.); \\ johannes.bischof@stud.sbg.ac.at (J.B.); peter.steinbacher@sbg.ac.at (P.S.) \\ 2 Department of Plastic and Reconstructive Surgery, Hospital of the Barmherzige Brüder, \\ Paracelsus Medical University Salzburg, 5020 Salzburg, Austria; elisabeth.russe@bbsalz.at (E.R.); \\ Gottfried.wechselberger@bbsalz.at (G.W.) \\ * Correspondence: klaus.richter@sbg.ac.at (K.R.); mark.rinnerthaler@sbg.ac.at (M.R.); \\ Tel.: +43-(0)-662-8044-5765 (K.R.); +43-(0)-662-8044-5791 (M.R.); Fax: +43-(0)-662-8044-144 (K.R. \& M.R.)
}

Received: 20 May 2018; Accepted: 31 May 2018; Published: 6 June 2018

\begin{abstract}
In previous publications, we could establish that a hallmark of human skin aging is the breakdown of the epidermal calcium gradient. This redistribution of calcium has many implications, including a restructuring of the cornified envelope, a reduced epidermal barrier function, a change in lipid composition, a reduced skin hydration, and an increased skin $\mathrm{pH}$. Especially the age-dependent change in the cornified envelope composition was solely studied in human foreskin samples. The aim of this study was to confirm that this effect is neither restricted to UV-protected skin area nor limited to a specific sex. In addition, we wanted to show that the collapse of the epidermal calcium gradient is not only a hallmark of human skin aging, but is also evolutionarily conserved in mammals. By using such techniques as IHC, Western blot analysis, and RT-PCR, we could demonstrate the following: (1) A change in the epidermal calcium gradient is in fact the most important sign of epidermal aging in mammals (as shown in female human eyelids and mouse skin samples of the external ear-shell); (2) The disturbed calcium homeostasis affects the expression and crosslinking of most cornified-envelope-specific genes such as loricrin and filaggrin. In this way, we could establish that the age-dependent altered composition of the cornified envelope is a typical sign of skin aging not only in humans, but in mice, too. This makes the mouse an important model organism to study these changes.
\end{abstract}

Keywords: skin aging; epidermal calcium gradient; cornified envelope; epidermal barrier; loricrin; filaggrin

\section{Introduction}

The epidermis is the main protective barrier against the surrounding environment in most vertebrate organisms. In mammals, this barrier consists of several key elements such as specific proteins, lipids, and a low skin $\mathrm{pH}$. The first two components are also known as the "brick and mortar" of the epidermis. In this model, the "bricks" are dead corneocytes that are filled with a large protein complex that is known as the cornified envelope (CE). The cornified envelope is comprised of many different proteins that get crosslinked and form the barrier against the environment. The space between the dead cells is filled with lipids that form the "mortar" [1]. These lipids are mainly $\omega$-OH-ceramides that are attached to the cornified envelope via ester bonds [2]. The key component in 
the formation of the epidermal barrier is calcium. This ion is responsible for the expression of different cornified envelope (CE)-specific proteins and acts as a cofactor for several enzymes that build up the protein scaffold during cornification of the epidermis [3,4]. This cornification process is initialized at the stratum spinosum by the expression of the proteins involucrin, envoplakin, and perilpakin, which are crosslinked and connected to the inner plasma membrane by the calcium-dependent transglutaminase-1. In this way, a protein monolayer is formed at the cytoplasmic side of the cell membrane. The next steps in the cornification process take place in the stratum spinosum and granulosum. The so-called lamellar bodies are formed by the Golgi apparatus and are filled with lipids (e.g., glucosylceramides, sphingomyelin, phospholipids, and cholesterol), hydrolytic enzymes, proteases, and several other proteins [5]. After an influx of calcium, these vesicular structures fuse with the cell membrane, thus replacing the phospholipid bilayer and secreting its content into the extracellular space. The main component of the cornified envelope $(\sim 80 \%)$ is the very insoluble protein loricrin $[6,7]$. By crosslinking loricirn to other proteins (all members of the small proline rich repeat (SPRR) protein family) via the transglutaminases 1 and 3, its solubility is raised [6]. This loricrin-SPRR complex is also cross-linked to the lipid-protein cover of the cell. Other CE-specific proteins like the calcium-regulated filaggrin, members of the S100 proteins, and late cornified envelope proteins (LCEs) are crosslinked to the cornified envelope of cornificated keratinocytes in the stratum granulosum [4]. The cornified envelope reaches its final differentiation state in the stratum corneum and finally sheds off. Calcium is the primary trigger for keratinocyte differentiation, which eventually leads to cell death. This implicates that calcium is also an antagonist for the proliferation of the stem cells in the stratum basale. To overcome this contradiction, the epidermis establishes a calcium gradient: In the stratum basale, only a low concentration of calcium is present and this concentration rises continuously reaching a peak in the stratum granulosum [4]. In previous publications, we demonstrated that a breakdown of the epidermal calcium gradient is the hallmark of aged human skin. The total amount of calcium in the epidermis does not change during aging, but the levels of calcium rise in the stratum basale and decline in the stratum granulosum. As we could show, this disturbed calcium homeostasis is linked to several age-specific phenotypes such as a reduced epidermal barrier (mainly attributed to reduced levels of loricrin), increased skin dryness (loss of filaggrin), and reduced wound healing [8].

The aforementioned study was based on human foreskin samples. Nothing is known if this calcium-mediated breakdown of the epidermal barrier is also detectable in other skin areas, in females, or even other mammals. The current study tries to fill this gap by using female eyelids and by testing the epidermal breakdown on mice.

\section{Materials and Methods}

Strains. Male and female mice from the wildtype background mice strain C57BL/6J from the Jackson Labortatories were used for this study. The group of young mice ( 3 male, 3 female) was analyzed after 4 weeks, the group of old mice after 96 to 102 weeks ( 3 male, 3 female). The mice were euthanized by cervical dislocation and the hairless skin of the external ear-shell was used for analysis.

Human Skin Samples. Human female eyelids were obtained after routine plastic surgery from the hospital "Barmherzige Brüder" (Salzburg, Austria). An informed consent was given from the patients.

RNA Isolation. Either human or mice skin tissue was homogenized in PeqGOLD Trifast (VWR Life Science, Heidelberg, Germany) using the the Ultra-Turrax T8 (IKA, Staufen, Germany). Afterwards, total RNA was isolated according to the manufacrtureres protocols.

cDNA Synthesis. A detailed cDNAsynthesis protocol is given in [9]. $1 \mu \mathrm{g}$ RNA was mixed with $2 \mu \mathrm{g}$ of an anchored oligo-dT-primer and transcribed into cDNA using Lucigen (Biozym, Hessisch Oldendorf, Germany) according to the manufacturer's instruction.

Real-time PCR. For human genes, the same primers were used as in Rinnerthaler et al. [8]. Primers used for RT-PCR of mice genes were created using the online available primer 3 software [10] and were ordered from Sigma-Aldrich Co. LLC, Saint Louis, MO, USA. The following settings were used (as described in [9]): product length was in the range of 150-200 bps, the primer length was set to 
18-22 bps with a Tm of $58-62{ }^{\circ} \mathrm{C}$, and the desired GC content was $40-60 \%$. All the primer sequences are summarized in Table 1. The GoTaq ${ }^{\circledR}$ qPCR Master Mix from Promega (Madison, WI, USA) was used for this study and the RT-PCR anylsis was carried out using a Rotor-Gene Q (Qiagen, Hilden, Germany). The following settings were used: 1 cycle: $95^{\circ} \mathrm{C} 240 \mathrm{~s} ; 40$ cycles: $95^{\circ} \mathrm{C} 10 \mathrm{~s}, 65 \mathrm{C} 15 \mathrm{~s}, 72{ }^{\circ} \mathrm{C}$ $15 \mathrm{~s}$, and $72{ }^{\circ} \mathrm{C}$ for $300 \mathrm{~s}$. To create melting curves, the PCR mixes were heated from $65^{\circ} \mathrm{C}$ to $95^{\circ} \mathrm{C}$. Because it was shown that beta actin does not change its expression in aged mouse skin [11], this gene was chosen as a reference for normalization. For human skin samples ARP (RPL0) was chosen for normalization. The formula $2^{-(\Delta \Delta C t)}$ was used to create the fold change.

Table 1. Real-Time PCR Primer Sequences.

\begin{tabular}{|c|c|c|c|c|c|}
\hline Gene & Orientation & Primer sequence $5^{\prime}-3^{\prime}$ & Gene & Orientation & Primer sequence $5^{\prime}-3^{\prime}$ \\
\hline \multirow{2}{*}{ Loricrin } & fwd & GTGGAAAGACCTCTGGTGGA & \multirow[b]{2}{*}{ SPRR2G } & fwd & GGGAAGGCATTTTTCTGAGAC \\
\hline & rev & TGGAACCACCTCCATAGGAA & & rev & GGAACATCCGTGACACACAG \\
\hline \multirow{2}{*}{ Filaggrin } & fwd & TCAAACAGGAGGGACAGACC & \multirow{2}{*}{ TGM2 } & fwd & GCCAGAGAACTGGGAGTCAG \\
\hline & rev & TATCСТСССТGACСАСТTGC & & rev & GGGTACAGGTCTGGTGCAGT \\
\hline \multirow{2}{*}{ Involucrin } & fwd & CCAGTGAAAGGAGACGTGCT & \multirow{2}{*}{ CSTA1 } & fwd & ACATTTGAGGCAACCCCATA \\
\hline & rev & TATGGGTGAGTAGGCCAGCT & & rev & GATGGTCTTCAAAAGCAACAAA \\
\hline \multirow{2}{*}{ SPRR2Jps } & fwd & TTTGCCAGCCTCCTCTTGTG & \multirow{2}{*}{ RPTN } & fwd & GGGATTTTGGACTTTGGTGA \\
\hline & rev & TTCTGCTGGCATGACTGAGG & & rev & CCATCAATGGAGGAAGAGGA \\
\hline \multirow{2}{*}{ LCE1D } & fwd & AAAGTGGTGCAGAAAGAACACA & \multirow{2}{*}{ PKP1 } & fwd & AGGGGAGCACTTAAGGCAAT \\
\hline & rev & GATGCAAAGAGGCATTGTCAT & & rev & GCCTACAGCAGTCTCCCTTG \\
\hline \multirow{2}{*}{ LCE3C } & fwd & AGGAGCTCCAGTTCCTGTGA & \multirow{2}{*}{ SPRR1A } & fwd & GCTGAGGCTGCTGTCTATCC \\
\hline & rev & AGAAGACTCTCCAGGATCAGAT & & rev & GGGCAATGTTAAGAGGCTCA \\
\hline \multirow{2}{*}{ S100A9 } & fwd & ACCAGGACAATCAGCTGAGC & \multirow{2}{*}{ SPRR1B } & fwd & GCTGAGCCTCAATTTGCATT \\
\hline & rev & TAGACTTGGTTGGGCAGCTG & & rev & GCTACCAAGTTCTCGGGTGA \\
\hline \multirow{2}{*}{ TGM1 } & fwd & TCAGATGCTGGAGGTGACAG & \multirow{2}{*}{ SPRR2A } & fwd & GGATCCACCTGTCTCTGCTC \\
\hline & rev & СССAGTCTTCСTGTCTGAGC & & rev & TATTACTGCСТССССТССТG \\
\hline \multirow{2}{*}{ TGM3 } & fwd & CAАAАСТСАААСССССТСАА & \multirow{2}{*}{ SPRR2B } & fwd & CTGTCTCACTGGCTCACCAA \\
\hline & rev & CAGGTGTGTGCTCAGTTGCT & & rev & AGGAAAGCAGCAGGAGATCA \\
\hline \multirow{2}{*}{ CDSN } & fwd & CACACCСТАСCAGACCСАTT & & fwd & AAGTGCCCACCTAAGAGCAA \\
\hline & rev & ATCCAGAGGGAACTGGGAGT & SPRKZD & rev & GGGGAAACATCTTCССТGTT \\
\hline & fwd & GCTGCTGACCTTCCTTCTTG & & fwd & AAGGCTGTCATGGGTGAATC \\
\hline PPL & rev & TGTTGGTGCCTGTCTTTCTG & SPRK2E & rev & CTGAGCATTTGGGACACTGA \\
\hline EVPL & fwd & GCCATGCTAGAAGGCTATCG & & fwd & TCAGGACAGGGGAAAGAGAA \\
\hline EVPL & rev & GTGGACACTCAGGAGGAGGA & SPRR2F & rev & CCCCTTTACAGCAGCAAGAT \\
\hline & fwd & CAGACCCTTGAGGAGCTGAC & & fwd & TCCCATCAGCATCAGAATCA \\
\hline SPRR3 & rev & AGAGGCTCTGGAGACACCTT & SPRR4 & rev & TGCTGTGCAGGACACTTCTC \\
\hline & fwd & GCTGCTGACCTGAGCAACTA & & fwd & GGAAATCACCATGCCCTCTA \\
\hline LCEIAI & rev & TGTCCCCAAGAAGACAAACC & S100A8 & rev & TGGCTGTCTTTGTGAGATGC \\
\hline JCF14? & fwd & GCTGCTGACCTGAGCAACTA & $5100 \triangle 7$ & fwd & CAGGCAGTCTCTCATCACCA \\
\hline LCE1A2 & rev & GGTCCTTCAAAAGGGGACAT & S100A7 & vrev & ACCCAGAACCATGACCTGAG \\
\hline & fwd & CCCTTGCACTTCAGACAAGC & & fwd & GGCCTAGGAGTTTGGTTTCC \\
\hline LCEIB & rev & TGTTTGCAAGGGGAGACTTT & CRCTI & rev & ACACTGCTGTGCACAACCTC \\
\hline LCE1C & fwd & GCTGACAAGTGCCATGAAGA & & fwd & CCAGTCAAGAGGACGAGAGG \\
\hline LCEIC & rev & GGGATTAGGTCATTGGGACA & S100A2 & rev & ACCTGCTGGTCACTGTCCTT \\
\hline & fwd & GCGGAGACAAGGAATTTCAG & & fwd & TGTCCTTCTCCATGCCTACC \\
\hline LCE3E & rev & ACCAGGGAATGAGGACTGTG & LELP1 & rev & CCACCACAAAAGCAAATCCT \\
\hline & fwd & GACCTGGAACATGATGCTGA & & fwd & ATCTTCССТCCAAAGCCATT \\
\hline LCE3D & rev & TCCACAGGAAAGATGGGAAC & SPRK2H & rev & CTGAGCATCTGGGACAGTGA \\
\hline ICF3C & fwd & AGGAGCTCCAGTTCCTGTGA & SPRR2I & fwd & TGCCTCCATAGCAACAACTG \\
\hline LCES & rev & AGAAGACTCTCCAGGATCAGAT & उРКरदा & rev & САTTCTCTGCAGGCCCTTTA \\
\hline $\mathrm{ICF} 3 \mathrm{~B}$ & fwd & AGCATCCTCAGACACGGACT & SPRR2K & fwd & СССТTCACAACСТСТCATGG \\
\hline LCEJD & rev & CACTGTGCTGTGCTCTTCCT & SPRKZK & rev & CAAAGGAAGGACCATTTCCA \\
\hline LCE3A & fwd & TTTGAGACAAAAGGGTTTGGA & LCE1I & fwd & TGACCTGGGTGAGGAAGACT \\
\hline LCE3A & rev & ACATGGTTGGACACAGGTGA & LCEII & rev & AATGGGCATTGTCGTTTCAT \\
\hline ICF1F & fwd & GACAAATGGGACAGGAGGAA & & fwd & CAAAGTGTCCCCCAAAATGT \\
\hline LCEIE & rev & TGTAACAAAGGGGAAACATGAA & LCE1) & rev & GCGATGGAGAGATCTGTGGT \\
\hline & fwd & TGCTAAGAAACTGGGCACAA & & fwd & TGTGGCAGTAGCCAACAGTC \\
\hline LCE6A & rev & TGTTGAACTGAAAGGGTAGGC & LCEIK & rev & GGGTAGCAACATGGGAACAA \\
\hline LCE1F & fwd & TGCTGCTGACCTGTATGAGG & LCE1L & fwd & GCTGACCTGGGTCATGAAG \\
\hline LCEIF & rev & TGCAGAACATTTCACAGGAGA & LCEIL & rev & TTGGAATCACAGAAGGAGATGA \\
\hline LCE1G & fwd & TCCTCATGAAATGACAATGACC & & fwd & GTCCСТCACССТCССAAAAG \\
\hline LCEIG & rev & GGCACAGTGTGTTTGAAGGA & Beta Actin & rev & CTCAGACCTGGGCCATTCAG \\
\hline AQP3 & fwd & CCA CAG CTT AGG TTT GGA GC & - & - & - \\
\hline AQPIO & rev & TCC CGG ATC CCT AAG ACT GT & - & - & - \\
\hline
\end{tabular}


Western Blot analysis. After heating the mouse skin to $60{ }^{\circ} \mathrm{C}$ for $2 \mathrm{~min}$, the epidermis was separated from the dermis. Afterwards, an extraction buffer $(0.0625 \mathrm{M}$ Tris-Cl, $5 \%$ SDS, $10 \%$ glycerol, $20 \%$ beta-Mercaptoethanol, $\mathrm{pH} 6.8$ ) was added to the epidermis samples (300 $\mu \mathrm{L}$ per $10 \mathrm{mg}$ epidermis) and they were homogenized using the Ultra-Turrax T8 (IKA). The homogenized epidermis was then heated to $95{ }^{\circ} \mathrm{C}$ for $15 \mathrm{~min}$. Equal protein amounts were loaded onto a $15 \%$ SDS-PAGE gel and were then blotted on nitrocellulose membranes with the following parameters: $250 \mathrm{~mA}, 90 \mathrm{~min}$ at RT. The membranes were then block by addition of MTBS-T (25mM TRIS pH 7.6, $137 \mathrm{mM} \mathrm{NaCl}$, $0.1 \%$ TWEEN 20,5\% nonfat milk powder) for $90 \mathrm{~min}$ at RT. After washing with TBS-T for $30 \mathrm{~min}$ the primary-antibodies were added and incubated over night at $8{ }^{\circ} \mathrm{C}$. The following primary antibodies were used: anti-loricrin antibody (LOR (C-13) (SC-51130; Santa Cruz Biotechnology, Santa Cruz, CA, USA); diluted 1:1000 in MTBS-T); anti-alpha-Tubulin antibody (sc-53030, Santa Cruz Biotechnology, Santa Cruz, CA, USA; diluted 1:1000 in MTBS-T). After removal of the primary antibody and three TBS-T wash steps (10 min at RT) the following secondary antibodies were added: an alkaline phosphatase conjugated affinity pure donkey anti goat IgG (s-2022, Santa Cruz Biotechnology, Santa Cruz, CA, USA; diluted 1:5000; in MTBS-T); a HRP conjugated goat anti rat secondary antibody (sc-2032, Santa Cruz Biotechnology, Santa Cruz, CA, USA; diluted 1:5000; in MTBS-T). In case of alkaline phosphatase, the WesternBlue stabilized substrate (Promega, Madison, WI, USA) was used for detection; in case of HRP, the -substrate Roti-Lumin (Carl Roth, Graz, Austria) was used.

Immunolabelling. By using a Leitz 1720 cryostat, serial skin sections (thickness $10 \mu \mathrm{m}$ ) were created from frozen human eyelids or mouse ear skin samples. The resulting skin sections were collected on poly-L-lysine coated slides, dried, and frozen. For immunostainings these samples were were fixed in $4 \%$ PFA, and washed in PBT (3 times for $3 \mathrm{~min}$ ). After blocking the skin sections with PBT-B-N (PBT with $2 \%$ BSA and 5\% normal rabbit serum) the following primary antibodies were added: a rabbit anti-LOR antibody (AF 62; Covance, Princeton, NJ, USA) (dilution 1:500 in PBT-B-N); anti-FLG antibody N20 (sc-25896, Santa Cruz Biotechnology, Santa Cruz, CA, USA) (dilution 1:250 in PBT-B-N);

The primary antibodies were incubated over night at $4{ }^{\circ} \mathrm{C}$ and the sections were then washed with PBT (3 times for $3 \mathrm{~min}$ ). After a second blocking step with with PBT-B-N the following secondary antibodies were added: an Alexa $488 \mathrm{~nm}$-conjugated goat anti rabbit (Molecular Probes, Grand Island, NY, USA) (1:600 diluted in PBT-B-N); HRP conjugated rabbit anti goat (Dako, Agilent, Santa Clara, CA, USA) (1:100 dilution).

The secondary antibody was incubated for $60 \mathrm{~min}$ and washed away with PBT (3 times for $3 \mathrm{~min})$. Finally, the skin sections were counterstained with Hoechst $33258(1 \mu \mathrm{g} / \mathrm{mL})$ and were then mounted in Gel/Mount (Biomeda, Foster City, CA, USA). Photographs were taken on a Reichert Polyvar microscope. For a quantitative comparison of samples, the identical microscope/camera settings (magnification $40 \times$, exposure time $2 \mathrm{~s}$ ) were applied.

Calcium-Staining and Detection. In the first step, Calcium-Green ${ }^{\mathrm{TM}}-1, \mathrm{AM}$ (ThermoFisher, Waltham, MA, USA) has to be activated (for details see [8]). A $2 \%$ low melting agarose was mixed with this activated dye $(1 \mu \mathrm{g} / \mathrm{mL})$ and the skin sections were overlaid. Finally, the calcium gradient was analyzed with fluorescence microscopy (excitation wavelength: $506 \mathrm{~nm}$; emission wavelength: $531 \mathrm{~nm}$ ).

ImageJ Analysis. The fluorescence intensity was additionally analyzed via a Java-based image processing program ImageJ (https:/ /imagej.nih.gov/ij/) by defining a square field size and placing the squares on the same lines from stratum basale to stratum corneum. By entering the computer command, the program analyzes the intensity by measuring the pixel intensity. The square field size was equal at all analyzed images; further, the values were normalized to the values of inner epidermal layers.

Statistics. A two-tailed, unpaired student's $t$-test was used to evaluate the data. Most data are displayed as arithmetic means \pm standard error of the mean (S.E.M). 


\section{Results}

\subsection{Breakdown of the Epidermal Calcium Gradient}

To check if the breakdown of the epidermal calcium gradient is in fact a general hallmark of human skin aging and not specific for a certain skin area or for a specific sex, 10 eyelids from females were analyzed that were obtained after a blepharoplasty. The age range of these skin tissues was from 41 to 72 years. According to their age two groups were formed: Middle age (5 skin samples: 41 years, 45 years, 2 times 47 years, 52 years) and old age ( 5 skin samples: 63 years, 64 years, 2 times 68 years, and 72 years). Cryostat preparations of these skin samples were overlaid with low melting agarose containing the calcium specific dye Calcium Green ${ }^{\mathrm{TM}}-1-\mathrm{AM}$ and were visualized using a fluorescence microscope. As can be seen in Figure 1, middle-aged individuals have a clear epidermal calcium gradient with a peak in the stratum granulosum. In aged female individuals, this gradient collapses and the calcium is equally distributed between all epidermal layers. No differences in fluorescence intensity were obvious between the stratum basale and stratum granulosum in aged skin samples (Figure 1).
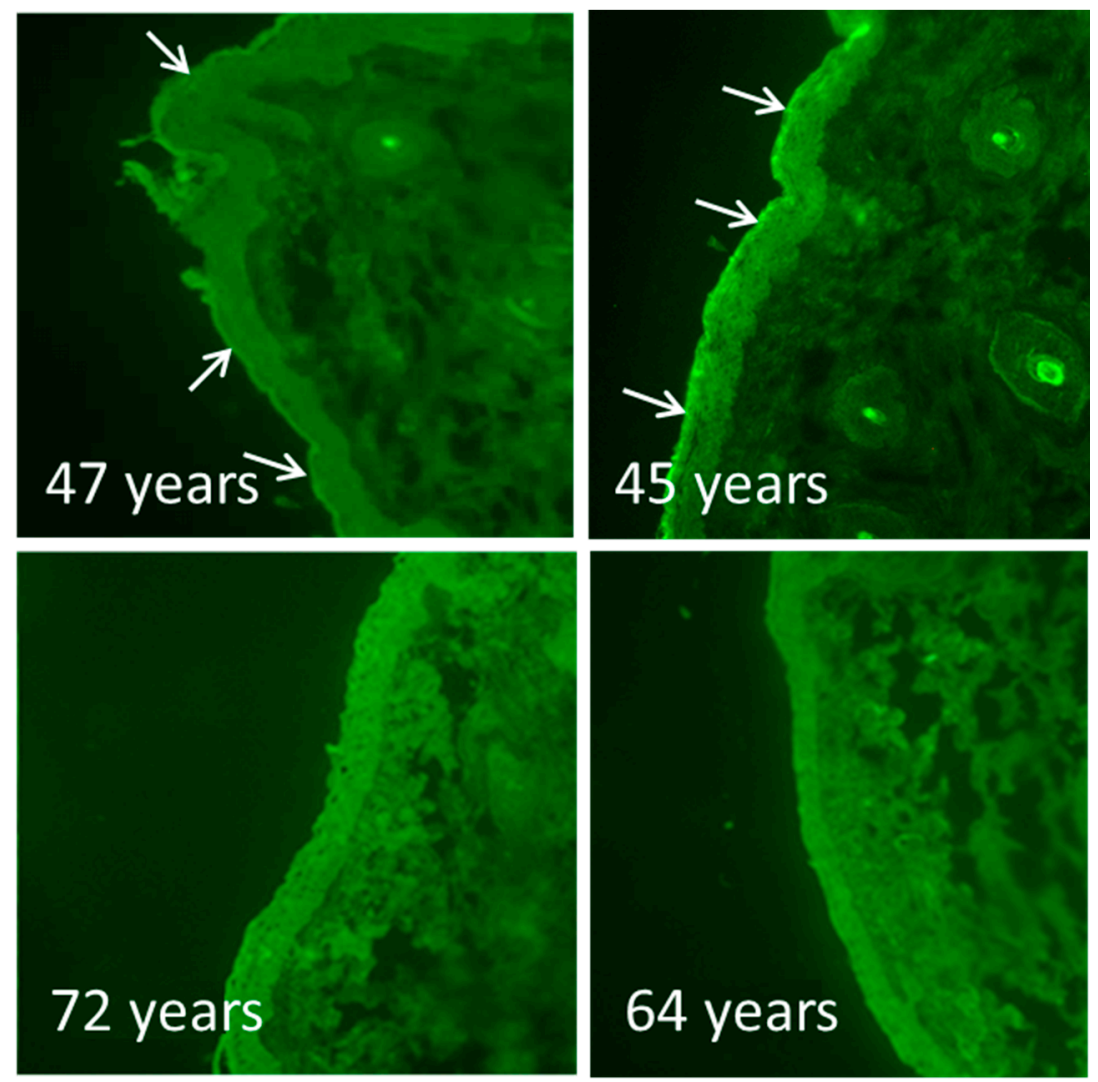

Figure 1. The epidermal calcium gradient in female human eyelids. The calcium distribution was stained using the calcium-specific dye Calcium-Green ${ }^{\mathrm{TM}}$ in cryosections of two old (birth year 1949 and 1953) and two middle-aged females (birth year 1969 and 1971). In the middle-aged skin sections, a peak of calcium in the stratum granulosum is clearly visible (indicated with white arrows), whereas the calcium is equally distributed in the aged skin sections.

\subsection{The Impact of the Collapsing Calcium Gradient on the Cornified Envelope Conposition}

In a previous publication with male skin tissues, a direct consequence of this calcium redistribution was a changed composition of the cornified envelope. To confirm these changes in female tissues, two observed phenotypes of aged foreskin samples were chosen due to their importance to the skin: a drop of filaggrin and a drop of loricrin. Especially the reduced levels of filaggrin have 
a backlash on skin hydration and therefore a third marker was chosen: AQP3. This protein is the most important aquaglyceroporin of the epidermis and is contributing to skin hydration and proliferation and differentiation of keratinocytes [12]. As can be seen in Figure 2A, the RNA levels of all three genes are dropping with increased age as shown by RT-PCR analysis: Loricrin RNA levels are 3-fold reduced, filaggrin levels ( $p$-value: 0.043) are more than 12-fold reduced, and AQP3 ( $p$-value: 0.059) levels show a nearly 60-fold reduction.

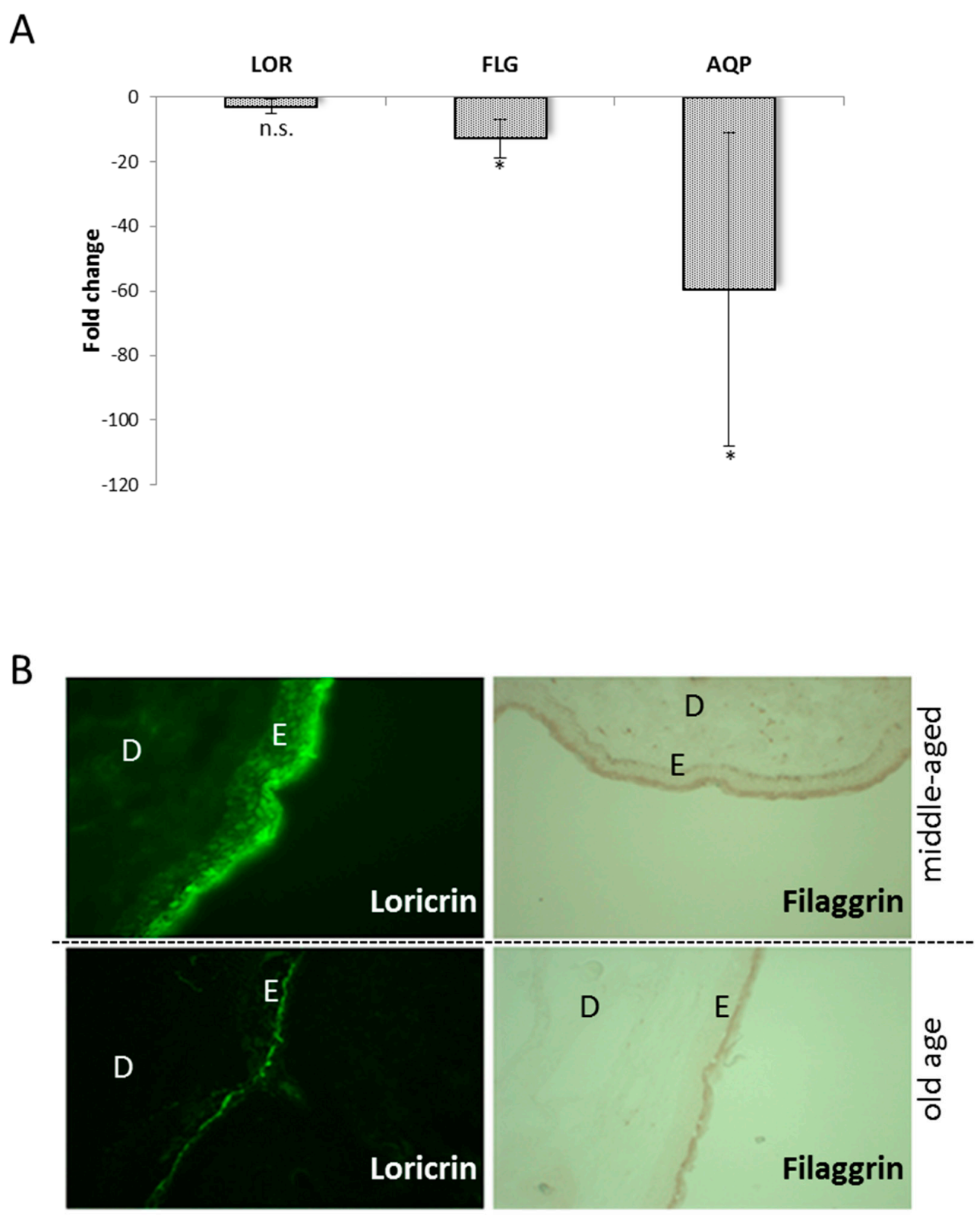

Figure 2. Protein composition of the cornified envelope. (A) RT-PCR analysis of filaggrin, loricrin, and AQP3 comparing 5 middle-aged with 5 old eyelids showed a decrease of these proteins with age. The values represent a mean \pm SEM, the significance of difference was analyzed by Student's $t$-test. (B) Immunohistochemical stainings of loricrin (secondary antibody is labelled with Alexa 488) and filaggrin (secondary antibody is HRP labelled) clearly show that both proteins are specifically expressed in the stratum granulosum and stratum corneum in female eyelids. The amount of both proteins is decreased in the old skin sections compared to middle-aged skin sections. E indicates the epidermis, $\mathrm{D}$ the dermis. 
These changes were also observed on protein levels. As can be seen on the histological sections (Figure 2B), loricrin is specifically expressed in the stratum granulsum (only low amounts of loricrin can be detected in the stratum spinosum) and no protein can be detected in the stratum basale. The distribution of loricrin is not different between middle-aged and old individuals but the amount of loricrin in the stratum granulosum is dramatically reduced in aged female eyelids (care was taken that exactly the same illumination times were used). In the case of filaggrin, the differences on the histological sections are less obvious. In middle-aged as well as old skin sections, filaggrin is solely found in the stratum granulosum. As expected, a reduction of filaggrin (although only a weak one) in the stratum granulosum can be seen in aged female eyelids (Figure 2B).

\subsection{Breakdown of the Epidermal Calcium Gradient in Mice}

In the next step, we wanted to test if the breakdown of the epidermal calcium gradient is not a specific marker for aged human skin, but is a universal hallmark of aged mammal skin. Therefore, an alteration in the calcium homeostasis and its feedback on the cornified envelope was tested in the important model organism mus musculus. As the most promising skin region of the mouse body, the external ear-shell was chosen. In this skin area, hair bulbs are completely absent and a certain similarity to human skin is obvious. Analogous to human skin, the epidermal calcium gradient was analyzed on skin sections by using the calcium specific dye Calcium Green ${ }^{\mathrm{TM}}-1$-AM. In total, 12 skin samples were analyzed ( 6 skin samples were obtained from young mice ( $\sim$ weeks old) and 6 from aged mice ( 100 weeks). In concordance to human skin we could also detected a calcium gradient in mice epidermis with a peak in the stratum granulosum and very low concentrations in the stratum basale (Figure 3A). Another phenotype is also very apparent: In mice skin, the epidermis is significantly thinner compared to human epidermis and this fact increases the difficulty to analyze the calcium gradient. Surprisingly, this calcium gradient did not completely collapse during aging but was less steep. Especially noticeable was the fact that the calcium concentration dramatically increased in the stratum basale in 100 weeks old mice. To quantify this age-dependent change in the epidermal calcium gradient, the decrease of the Calcium-Green ${ }^{\mathrm{TM}}$ fluorescence in the stratum garnulosum) the software ImageJ was used. By using this software, the ratio between the fluorescence intensity of the inner layers (stratum basale and spinosum) and the outer layers (stratum granulosum and corneum) was determined. In young mice, the fluorescence intensity of the stratum granulosum is 8-fold higher than in the stratum basale, and in old mice this ratio is almost reduced by $50 \%$.

\subsection{Altered Cornified Envelope Composition}

Thereafter, we wanted to test if these reduced levels of calcium in the stratum granulsoum lead to a changed composition of the cornified envelope. As the marker protein for this potential change, loricrin was chosen. Similar to humans, loricrin is the most abundant protein of the cornified envelope in mice ( $70 \%$ by mass). In contrast to humans, where changes in loricrin levels or mutations lead to severe diseases such as Vohwinkel's disease or progressive symmetric erythrokeratoderma (PSEK) [13,14], a loss of loricrin has a very mild phenotype in mice [15]. On histological skin sections, immunohistochemistry revealed that loricrin resides in the stratum garnulosum/corneum (Figure 4A). Loricrin was stained with a specific primary antibody and was visualized with an Alexa 488-conjugated secondary antibody. When comparing young and old mouse skin sections, the amounts of loricrin are clearly reduced, although the phenotype is less prominent than in human aging. The phenotype is much more obvious with Western blot analysis comparing young female, young male, old female, and old male epidermal protein extracts. The loricrin levels are slightly varying between the sexes, but a clear decline of loricrin could be seen in the $\sim 100$-weeks-old mice (Figure 4B). The drop of loricrin was quantified using ImageJ and a $~ 10$-fold reduced level of loricrin was found in aged mice (Figure 4C). 
A
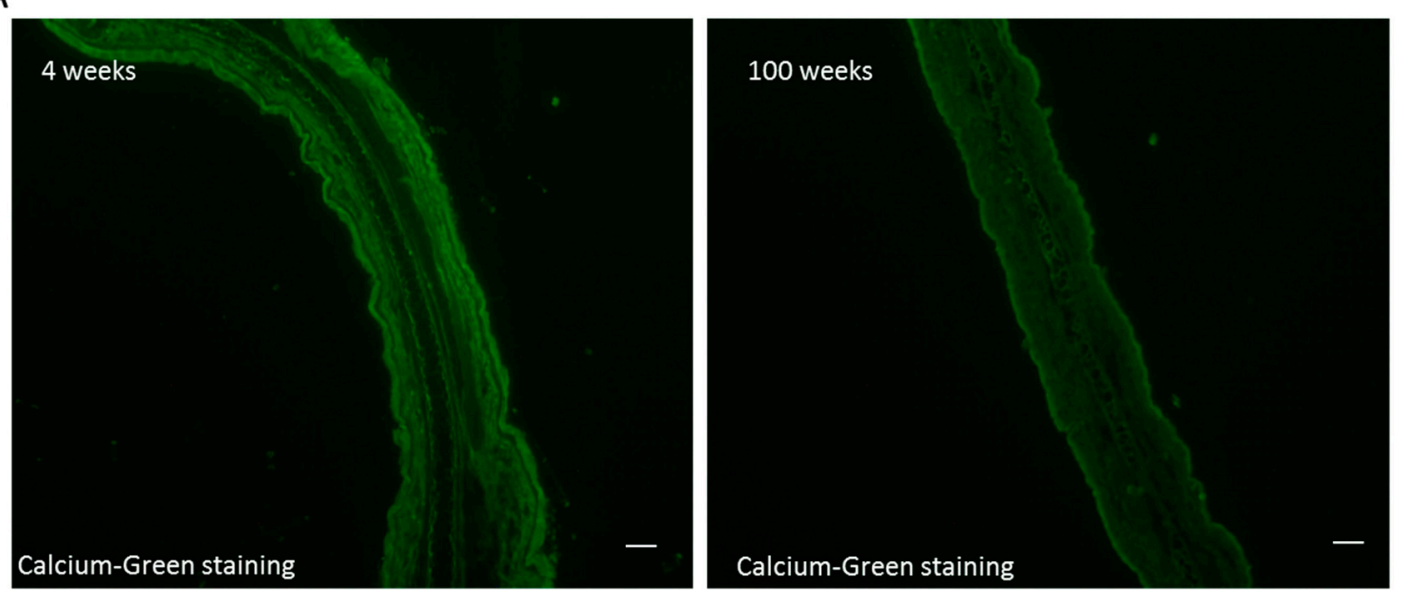

B

C
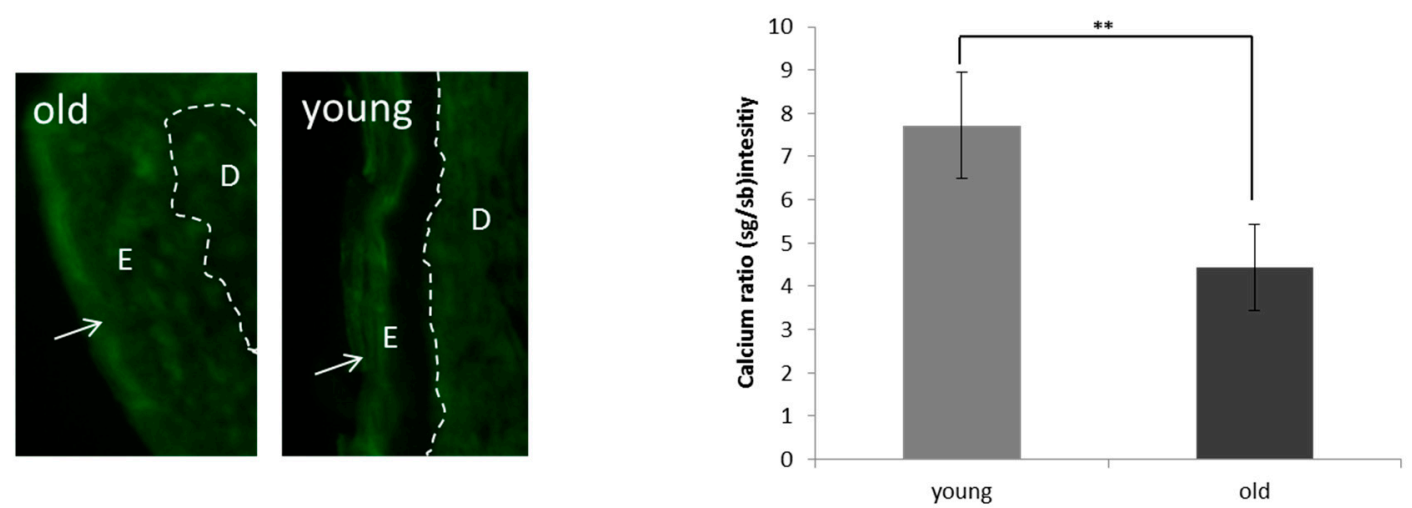

Figure 3. The epidermal calcium gradient in of the external ear shell of mice. (A) The calcium distribution was stained with Calcium-Green TM in cryosections of old and young mice ears. On both sides of the ear, the epidermis can be seen that encloses the dermis. (scale bar: $100 \mu \mathrm{m}$ ) (B) A magnification of the Calcium-Green ${ }^{\mathrm{TM}}$ stained cryosections. Identical to human skin, an epidermal calcium gradient can be seen in the young skin section with a peak in the stratum granulosum. In aged mice ears, the amount of calcium in the stratum granulosum decreases and the concentration of calcium rises in the stratum basale (the dotted line represents the zone between dermis (D) and epidermis (E); the white arrow pints to the stratum granulosum)). (C) The decrease of calcium at the outer epidermal layers was additionally analyzed via the imaging software ImageJ. The calcium levels of the stratum granulosum were normalized to the calcium levels at the inner epidermal layers (stratum basale) and $\sim 2$-fold significant decrease of this ratio was measured during aging.

\subsection{Transcriptional Profile of CE Specific Genes}

To study the impact of the collapsing calcium gradient on the cornified envelope in more detail, a transcription profile of cornified envelope specific genes in young and aged mice was established. Therefore, 50 genes specific for the cornifed envelope were analyzed via RT-PCR (see Figure 5 and Table 2) in 12 mice (C57BL/6J background). Six of these mice had an average age of 102 weeks, and 6 mice had an average age of 4 weeks. Summarized in Figure 5A are the scaffold proteins of the cornified envelope (involucrin, evoplakin, and peripkalin) as well as the most abundant proteins of the CE (such as loricrin and filaggrin). In Figure 5B, the RT-PCR data of the small proline rich repeat protein family as well as some S100 proteins are shown; in Figure 5C data on the whole late cornified envelope family is presented. Some of the highlights are discussed. The first proteins that are formed in the cornification process are the two plakins envoplakin and periplakin and their transcription is nearly unaffected during the aging process. Involucrin and filaggrin show just slightly increased RNA levels 
(both 1.8-fold) during aging, whereas loricrin, the most abundant component of the cornified envelope, seems to be upregulated. This apparent contradiction between the RNA data and protein data will be addressed in the discussion section. As can be seen in Figure 5B, most of the small proline rich repeat proteins are upregulated, whereas most tested S100 proteins are downregulated. For example, the levels of S100A2 are more than 200-fold decreased. Other targets of TGMs are the late cornified envelope proteins (LCEs) that are connected to the protein scaffold at a later time point of keratinocyte differentiation. In sum, all these data indicate in mice, similar to humans, that the cornified envelope under the influence of the collapsing calcium gradient is heavily rebuilt and the epidermal barrier gets defective.

A
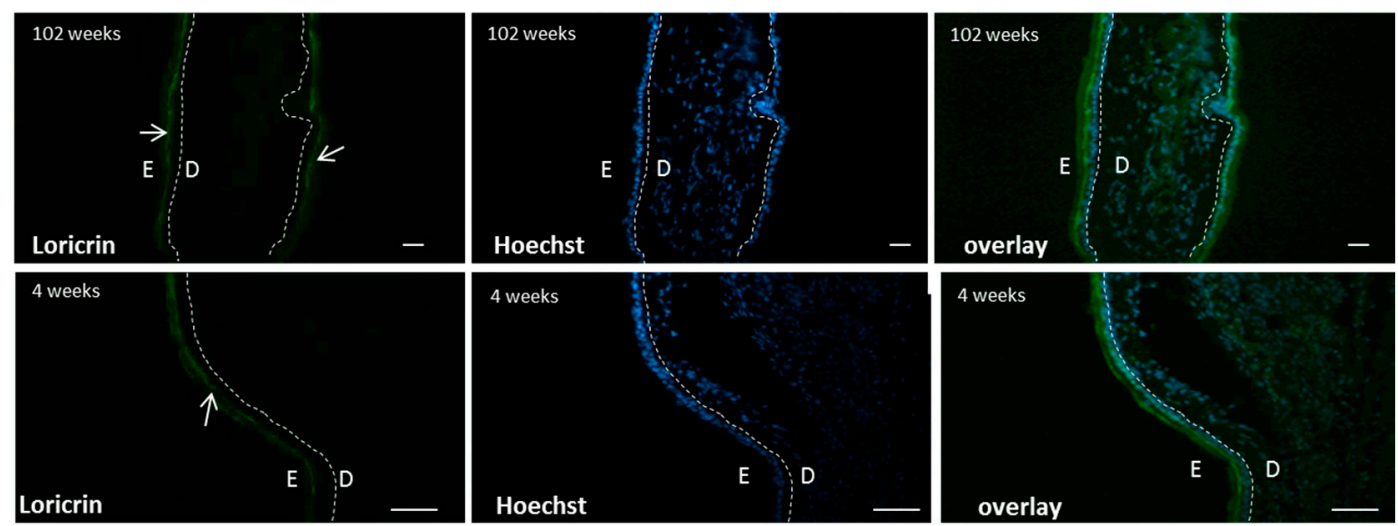

B

\section{C}
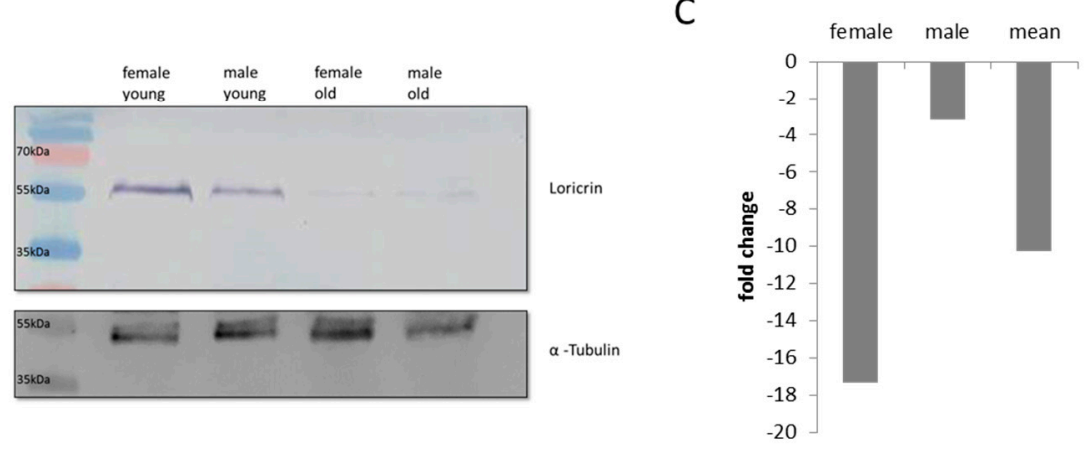

Figure 4. Loricrin distribution and concentration in young and old mice skin. (A) Immunofluorescence of loricrin in the stratum granulosum and corneum during aging. In the stratum basale and stratum spinosum, nearly no loricrin is detectable in young and old individuals. Hoechst 33258 was used as counterstaining; the dotted line represents the zone between dermis (D) and epidermis (E). The white arrows point to the loricrin in the stratum granulosum (scale bar: $100 \mu \mathrm{m}$ ). (B) Western blot analysis of two young and two old mice skin protein extracts using an anti-loricrin antibody. In the two aged skin extracts, the protein concentration is clearly decreased when compared to the young skin samples. An anti- $\alpha$-tubulin antibody was used as a loading control. In (C) the decline of loricrin during aging was quantified using ImageJ (in the mean 10-fold decreased).

Positive values indicate an upregulation of genes during the ageing process, negative values indicate a downregulation. The dotted lines represent the chosen cut-off value for a significant fold change of 1.5. (A) shows the regulation of most prominent cornified envelope genes (loricirn, envoplakin, involucrin, loricrin, filaggrin, and the transglutminases). (B) includes all members of the small proline rich repeat family and some $\mathrm{S} 100$ proteins. In $(\mathrm{C})$, the regulation of all members of the late cornified envelop protein family can be found. The $p$-values of this analysis are summarized in Table 2. 
A

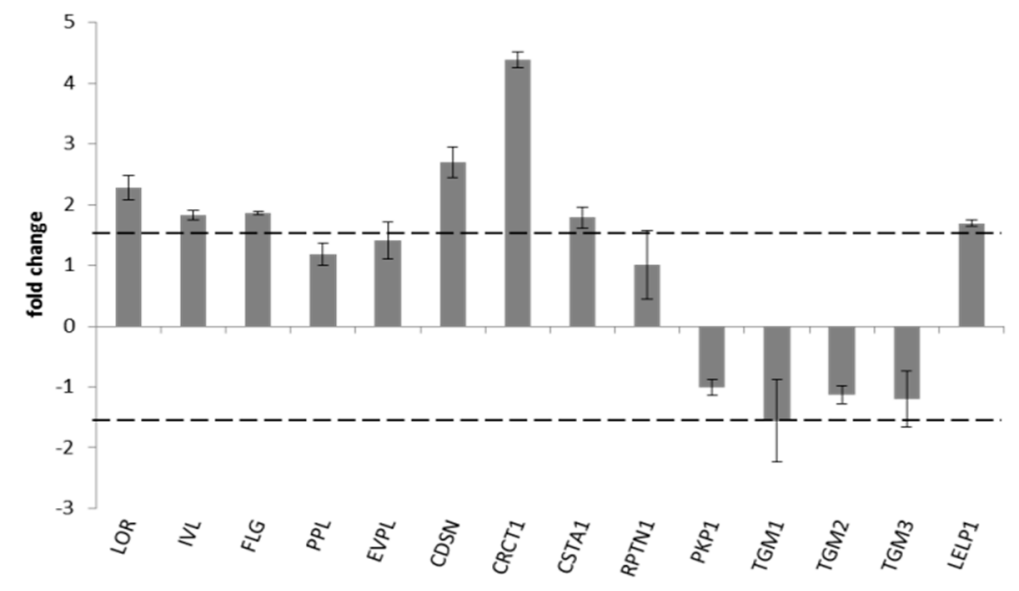

B

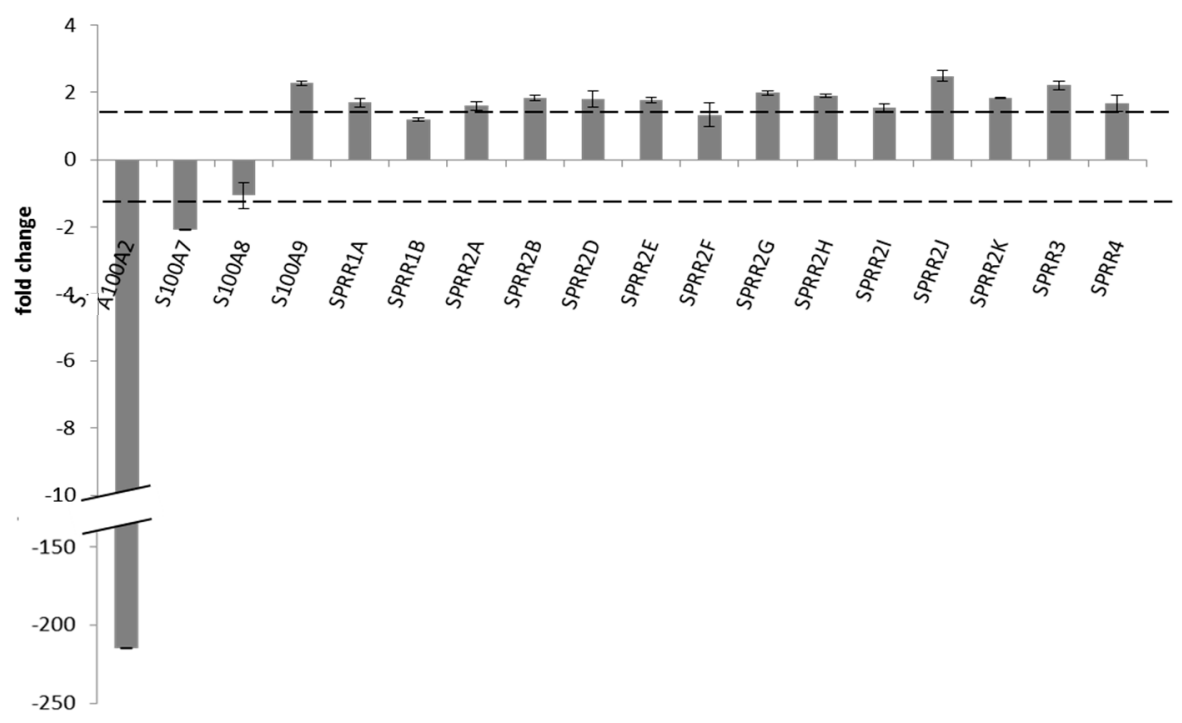

C

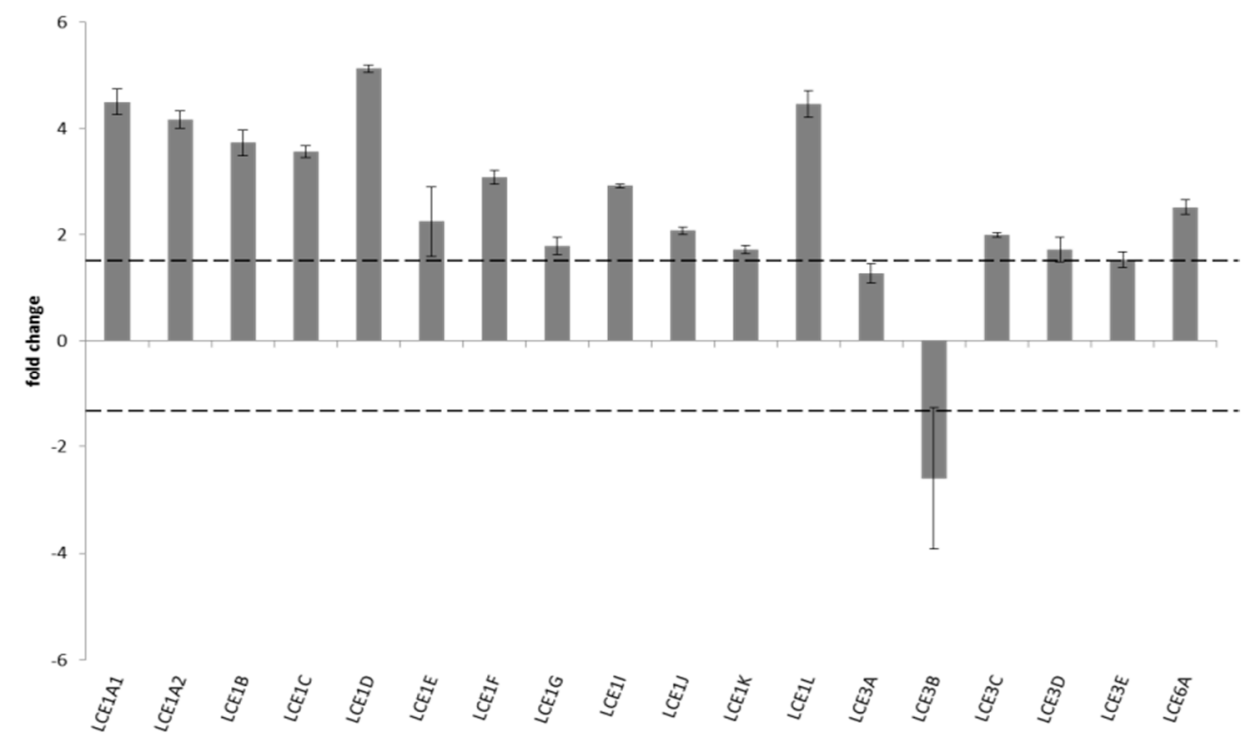

Figure 5. RT-PCR analysis of cornified envelope specific gene. 
Table 2. Cycling thresholds and $p$-values of all the cornified envelope specific genes that are shown in Figure 5. $\Delta \mathrm{Ct}$ values presented in this table were generated by normalization to the housekeeping gene beta-actin. Positive values indicate a lower transcription level, negative values indicate a higher transcription level, when compared to beta actin.

\begin{tabular}{|c|c|c|c|c|c|}
\hline Gene & $\begin{array}{c}\varnothing \Delta \mathrm{Ct} \text { ys } \\
(n=6)\end{array}$ & $\begin{array}{c}\text { SEM } \\
\varnothing \Delta \mathrm{Ct} \text { ys }(n=6)\end{array}$ & $\begin{array}{c}\varnothing \Delta \mathrm{Ct} \text { os } \\
(n=6)\end{array}$ & $\begin{array}{c}\text { SEM } \\
\varnothing \Delta \mathrm{Ct} \text { os }(n=6)\end{array}$ & $p$-Value (ys-os) \\
\hline LOR & 5.03 & 0.3612882 & 3.8425 & 0.19493945 & 0.0133 \\
\hline IVL & 2.74833333 & 0.22913182 & 1.8825 & 0.07959097 & 0.0040 \\
\hline FLG & 3.765 & 0.12894336 & 2.8625 & 0.02568506 & 0.0037 \\
\hline CDSN & 2.91333333 & 0.14708746 & 1.4825 & 0.25663149 & 0.0109 \\
\hline CRCT1 & 3.20333333 & 0.22338619 & 1.0725 & 0.12823048 & 0.0009 \\
\hline CSTA1 & 3.566666667 & 0.32272925 & 2.7275 & 0.17311284 & 0.0689 \\
\hline TGM1 & 4.93333333 & 0.19329382 & 5.57416667 & 0.6776563 & 0.285 \\
\hline LELP1 & 3.315 & 0.30997984 & 2.5525 & 0.04826144 & 0.0295 \\
\hline $\mathrm{A} 100 \mathrm{~A} 2$ & 5.297 & 0.20829066 & 13.0441667 & 0.22215172 & 0.0001 \\
\hline S100A7 & 1.41333333 & 0.14077662 & 2.46416667 & 0.01767767 & 0.0195 \\
\hline S100A9 & 2.70666667 & 0.25035808 & 1.52083333 & 0.06124858 & 0.0106 \\
\hline SPRR1A & 2.286666667 & 0.30113904 & 1.53083333 & 0.12780736 & 0.0421 \\
\hline SPRR2A & 0.19833333 & 0.05606296 & -0.48083333 & 0.1255488 & 0.0710 \\
\hline SPRR2B & 2.63833333 & 0.06172295 & 1.76416667 & 0.08603133 & 0.0060 \\
\hline SPRR2D & 10.2283333 & 0.79166053 & 9.37583333 & 0.24859885 & 0.4486 \\
\hline SPRR2E & 3.425 & 0.26437295 & 2.61083333 & 0.08327498 & 0.0763 \\
\hline SPRR2G & 2.476666667 & 0.20021169 & 1.49083333 & 0.07315319 & 0.0550 \\
\hline SPRR2H & 3.03 & 0.30980056 & 2.1175 & 0.04891887 & 0.0827 \\
\hline SPRR2I & 2.41166667 & 0.2943708 & 1.77916667 & 0.10552119 & 0.1783 \\
\hline SPRR2J & 2.975 & 0.5721997 & 1.66583333 & 0.16571813 & 0.0262 \\
\hline SPRR2K & 5.63833333 & 0.50090335 & 4.75916667 & 0.01504623 & 0.2473 \\
\hline SPRR3 & 2.89166667 & 0.48133062 & 1.75416667 & 0.12045631 & 0.0454 \\
\hline SPRR4 & 5.84666667 & 0.67670259 & 5.10416667 & 0.24363851 & 0.3486 \\
\hline LCE1A1 & 2.11666667 & 0.05635946 & -0.05083333 & 0.24534273 & 0.0001 \\
\hline LCE1A2 & 2.36166667 & 0.09449427 & 0.3025 & 0.16478521 & 0.0004 \\
\hline LCE1B & 2.725 & 0.12471634 & 0.82916667 & 0.24769773 & 0.0071 \\
\hline LCE1C & 2.565 & 0.27731601 & 0.73416667 & 0.11885449 & 0.0005 \\
\hline LCE1D & 2.35666667 & 0.32636253 & 0.00083333 & 0.06795628 & 0.0004 \\
\hline LCE1E & 4.21666667 & 0.61893838 & 3.0525 & 0.65375943 & 0.2335 \\
\hline LCE1F & 2.49833333 & 0.39387145 & 0.88083333 & 0.12817631 & 0.0085 \\
\hline LCE1G & 3.31333333 & 0.60679829 & 2.4775 & 0.16788306 & 0.186 \\
\hline LCE1I & 2.53 & 0.20341187 & 0.9875 & 0.0274621 & 0.0054 \\
\hline LCE1J & 3.25 & 0.36124976 & 2.20083333 & 0.06133922 & 0.0268 \\
\hline LCE1K & 3.42166667 & 0.3042226 & 2.64416667 & 0.0803724 & 0.1721 \\
\hline LCE1L & 3.00666667 & 0.2834828 & 0.8525 & 0.25470844 & 0.0007 \\
\hline LCE3B & 7.88333333 & 0.67345193 & 9.26083333 & 1.3296496 & 0.3363 \\
\hline LCE3C & 3.23166667 & 0.28404078 & 2.23916667 & 0.04677072 & 0.0086 \\
\hline LCE3D & 2.82 & 0.32581309 & 2.04083333 & 0.22607459 & 0.0744 \\
\hline LCE3E & 2.67833333 & 0.28519243 & 2.06916667 & 0.14301806 & 0.1548 \\
\hline LCE6A & 2.42 & 0.23960906 & 1.08916667 & 0.13181953 & 0.0018 \\
\hline
\end{tabular}

\section{Discussion}

In the course of this project we could demonstrate that the collapse of the epidermal calcium gradient is a general hallmark of aging skin in mammals. Previously, we and others $[7,8,16]$ could demonstrate that in human foreskin and facial skin the amount of calcium in the stratum granulosum decreases during aging, whereas the concentration of calcium in the stratum basale rises. In the current study, we could show that this phenotype is not specific for males, but can be confirmed for females, too. In aged mice, the epidermal calcium gradient persists but is less steep when compared to 4-week-old mice. At the moment, it is still unclear what kind of mechanism lies behind this altered calcium distribution, but the underlying problems seem to be evolutionary conserved in mammals. Although 
we cannot say anything about the reason, the downstream effects are very obvious. Calcium is the main driver of keratinocyte differentiation and influences this cell type on several levels [4]. High calcium levels promote directly or indirectly the expression of many (if not all) cornified-envelope-specific genes. Additionally, calcium is an important cofactor for the enzyme class of transglutaminases. These enzymes catalyze the crosslinking of skin specific proteins (e.g., loricirn, involucin, periplakins envoplakins, and SPRRs) leading to the formation of the cornified envelope that constitutes the main component of the epidermal barrier besides lipids [17]. Therefore, it is obvious that the cornified envelopes get defective with age. In aged female eyelids, we could show that the amount of the loricrin decreases (on RNA as well as protein level). Because loricrin is the most abundant protein of the cornified envelope, the barrier function of this protein complex gets defective and it can be speculated that this leads to chronic infections of the skin as well as a reduced wound healing, both phenotypes that are very common in age. Filaggrin is another protein that is specifically expressed in the stratum granulosum and is of great importance for keratinocytes/corneocytes. It also shows reduced expression levels with age. Filaggrin contributes on many levels to the establishment of the epidermal barrier. Filaggrin is crosslinked to the cornified envelope and also contributes to the acidic skin $\mathrm{pH}$. Finally, filaggrin is degraded to hygroscopic amino acids that are essential for the moisture of the skin [18]. The observed drop of filaggrin can therefore explain many age specific phenotypes of the skin: an increased rate of infection, increased skin dryness, and a higher skin $\mathrm{pH}$ [19]. The decrease of skin hydration is additionally increased by decrease of AQP3 expression during aging that we demonstrated in this study.

Surprisingly, the observed phenotypes with female eyelids in this study were less pronounced than with male foreskin samples that showed lower levels of loricrin and filaggrin. However, we assume that there are other reasons responsible than sex. These variances can be explained by two factors: age difference and photoaging. In the study on foreskin samples, the young and old adults had a huge age gap of more than 40 years. In the present eyelid study, the age difference between the middle aged and old group was only 21 years on the average. The second factor is even more important. UV-irradiation leads to DNA mutations, damage to proteins, ROS production at cellular chromophores, and degradation of the extracellular matrix in the dermis. All together, these components lead to a faster aging of the skin [7]. The factor photoaging is nearly absent in foreskin samples and is very pronounced in eyelids. Therefore, it seems plausible that in female eyelids the effects of the collapsing calcium gradient are slightly diminished. Nevertheless, they are still clearly detectable.

Similar to human skin, the reduced calcium levels in the stratum granulosum lead to an altered composition of the cornified envelope in mice. The main hallmark is a reduced loricrin content in the stratum garnulosum of aged mice. Although the protein level decreases $\sim 8$-fold, the RNA level increases more than 2-fold. This clearly indicates that loricrin in aged skin shows a higher turnover and the keratinocytes try to cope with the loss of loricrin with a higher transcription of this gene. In the year 2000, Koch et al. [15] showed that loricrin knockout mice did not have a decreased epidermal barrier. These authors speculated that the loss of loricrin is compensated for by an increased expression of several cornified envelope components, especially the small proline rich repeat proteins. In fact, we also observe an increased expression of this protein family previously [8], as well in this study. There is also another explanation for the increased levels of the SPRRs. It was demonstrated that this protein family has high anti-oxidative properties due to their high cysteine content [20]. This fit quite well to the "Free Radical Theory of Aging" that is one of the most prominent aging theories. It claims that the so-called reactive oxygen species (ROS) dramatically increase at the end of life and start to react with all organic components of the cell [21]. Therefore, it would make sense to increase the expression of the SPRRs during aging to quench these dangerous reactive molecules.

The highest change in expression from young to aged we found was within the family of S100 proteins, S100A2 (-214.8-fold), a member of this calcium-binding EF-hand protein family. It is reported that S100A2 may control the expression of numerous calcium channels like SLC11A1, SLC5A2, ATP2C1, SLC16A10, and MCOLN3 [22]. It could be hypothesized that one of these calcium channels might 
be involved in the establishment of the epidermal calcium gradient. For example, Hailey-Hailey disease in human skin is attributed to a mutation of ATP2C1. A direct consequence is an altered epidermal calcium gradient similar to aging [23]. This of course could lead to the speculation that a decrease of S100A2 may result in a loss of ATP2C1 during aging with the consequence of the calcium gradient collapsing.

The parallelism between human and mice skin aging makes mus musculus a perfect model for research. This could help to understand the establishment of the epidermal calcium gradient as well as its collapse, and pharmaceutical interventions that sustain the calcium gradient could be developed and tested in this mouse model.

Author Contributions: M.R., G.W., and K.R. designed experiments. M.R. and K.R. wrote the paper. M.K.S., J.B., C.N., P.S., and E.R. performed the experiments.

Funding: This research was funded by the OeAD/WTZ for the project CZ 10/2014 to M.R.

Acknowledgments: We are especially thankful to Peter Hammerl for his assistance in animal care and management.

Conflicts of Interest: We declare no conflict of interest.

\section{References}

1. Nemes, Z.; Steinert, P.M. Bricks and mortar of the epidermal barrier. Exp. Mol. Med. 1999, 31, 5-19. [CrossRef] [PubMed]

2. Marekov, L.N.; Steinert, P.M. Ceramides are bound to structural proteins of the human foreskin epidermal cornified cell envelope. J. Biol. Chem. 1998, 273, 17763-17770. [CrossRef] [PubMed]

3. Streubel, M.K.; Rinnerthaler, M.; Bischof, J.; Richter, K. Changes in the Composition of the Cornified Envelope during Skin Aging: A Calcium Centric Point of View. In Textbook of Aging Skin; Farage, M.A., Miller, K.W., Maibach, H.I., Eds.; Springer: Berlin/Heidelberg, Germany, 2017; pp. 265-284.

4. Rinnerthaler, M.; Streubel, M.K.; Bischof, J.; Richter, K. Skin aging, gene expression and calcium. Exp. Gerontol. 2015, 68, 59-65. [CrossRef] [PubMed]

5. Raymond, A.A.; Gonzalez de Peredo, A.; Stella, A.; Ishida-Yamamoto, A.; Bouyssie, D.; Serre, G.; Monsarrat, B.; Simon, M. Lamellar bodies of human epidermis: Proteomics characterization by high throughput mass spectrometry and possible involvement of clip-170 in their trafficking/secretion. Mol. Cell. Proteom. 2008, 7, 2151-2175. [CrossRef] [PubMed]

6. Kalinin, A.; Marekov, L.N.; Steinert, P.M. Assembly of the epidermal cornified cell envelope. J. Cell. Sci. 2001, 114, 3069-3070. [PubMed]

7. Rinnerthaler, M.; Bischof, J.; Streubel, M.K.; Trost, A.; Richter, K. Oxidative stress in aging human skin. Biomolecules 2015, 5, 545-589. [CrossRef] [PubMed]

8. Rinnerthaler, M.; Duschl, J.; Steinbacher, P.; Salzmann, M.; Bischof, J.; Schuller, M.; Wimmer, H.; Peer, T.; Bauer, J.W.; Richter, K. Age-related changes in the composition of the cornified envelope in human skin. Exp. Dermatol. 2013, 22, 329-335. [CrossRef] [PubMed]

9. Lener, T.; Moll, P.R.; Rinnerthaler, M.; Bauer, J.; Aberger, F.; Richter, K. Expression profiling of aging in the human skin. Exp. Gerontol. 2006, 41, 387-397. [CrossRef] [PubMed]

10. Untergasser, A.; Cutcutache, I.; Koressaar, T.; Ye, J.; Faircloth, B.C.; Remm, M.; Rozen, S.G. Primer3-new capabilities and interfaces. Nucleic Acids Res. 2012, 40. [CrossRef] [PubMed]

11. Yoo, J.; Omori, M.; Gyarmati, D.; Zhou, B.H.; Aye, T.; Brewer, A.; Comeau, M.R.; Campbell, D.J.; Ziegler, S.F. Spontaneous atopic dermatitis in mice expressing an inducible thymic stromal lymphopoietin transgene specifically in the skin. J. Exp. Med. 2005, 202, 541-549. [CrossRef] [PubMed]

12. Boury-Jamot, M.; Daraspe, J.; Bonte, F.; Perrier, E.; Schnebert, S.; Dumas, M.; Verbavatz, J.M. Skin aquaporins: Function in hydration, wound healing, and skin epidermis homeostasis. Handb. Exp. Pharmacol. 2009, 205-217. [CrossRef]

13. Korge, B.P.; IshidaYamamoto, A.; Punter, C.; DoppingHepenstal, P.J.C.; Iizuka, H.; Stephenson, A.; Eady, R.A.J.; Munro, C.S. Loricrin mutation in vohwinkel's keratoderma is unique to the variant with ichthyosis. J. Investig. Dermatol. 1997, 109, 604-610. [CrossRef] [PubMed] 
14. Ishida-Yamamoto, A.; Takahashi, H.; Iizuka, H. Loricrin and human skin diseases: Molecular basis of loricrin keratodermas. Histol. Histopathol. 1998, 13, 819-826. [PubMed]

15. Koch, P.J.; de Viragh, P.A.; Scharer, E.; Bundman, D.; Longley, M.A.; Bickenbach, J.; Kawachi, Y.; Suga, Y.; Zhou, Z.J.; Huber, M.; et al. Lessons from loricrin-deficient mice: Compensatory mechanisms maintaining skin barrier function in the absence of a major cornified envelope protein. J. Cell. Biol. 2000, 151, 389-400. [CrossRef] [PubMed]

16. Denda, M.; Tomitaka, A.; Akamatsu, H.; Matsunaga, K. Altered distribution of calcium in facial epidermis of aged adults. J. Investig. Dermatol. 2003, 121, 1557-1558. [PubMed]

17. LaCelle, P.T.; Lambert, A.; Ekambaram, M.C.; Robinson, N.A.; Eckert, R.L. In vitro cross-linking of recombinant human involucrin. Skin Pharmacol. Appl. 1998, 11, 214-226. [CrossRef] [PubMed]

18. Kezic, S.; Jakasa, I. Filaggrin and skin barrier function. Curr. Probl. Dermatol. 2016, 49, 1-7. [PubMed]

19. Choi, E.H.; Man, M.Q.; Xu, P.; Xin, S.J.; Liu, Z.L.; Crumrine, D.A.; Jiang, Y.J.; Fluhr, J.W.; Feingold, K.R.; Elias, P.M.; et al. Stratum corneum acidification is impaired in moderately aged human and murine skin. J. Investig. Dermatol. 2007, 127, 2847-2856. [CrossRef] [PubMed]

20. Vermeij, W.P.; Alia, A.; Backendorf, C. Ros quenching potential of the epidermal cornified cell envelope. J. Investig. Dermatol. 2011, 131, 1435-1441. [CrossRef] [PubMed]

21. Harman, D. Aging-A theory based on free-radical and radiation-chemistry. J. Gerontol. 1956, 11, $298-300$. [CrossRef] [PubMed]

22. Matsubara, D.; Niki, T.; Ishikawa, S.; Goto, A.; Ohara, E.; Yokomizo, T.; Heizmann, C.W.; Aburatani, H.; Moriyama, S.; Moriyama, H.; et al. Differential expression of s100a2 and s100a4 in lung adenocarcinomas: Clinicopathological significance, relationship to p53 and identification of their target genes. Cancer Sci. 2005, 96, 844-857. [CrossRef] [PubMed]

23. Sudbrak, R.; Brown, J.; Dobson-Stone, C.; Carter, S.; Ramser, J.; White, J.; Healy, E.; Dissanayake, M.; Larregue, M.; Perrussel, M.; et al. Hailey-hailey disease is caused by mutations in $A T P_{2} C_{1}$ encoding a novel $\mathrm{Ca}^{2+}$ pump. Hum. Mol. Genet. 2000, 9, 1131-1140. [CrossRef] [PubMed]

(C) 2018 by the authors. Licensee MDPI, Basel, Switzerland. This article is an open access article distributed under the terms and conditions of the Creative Commons Attribution (CC BY) license (http:/ / creativecommons.org/licenses/by/4.0/). 